ISSN 1112-9867

http://www.jfas.info

\title{
HEALTH RISKS ZONATION IN MEGACITIES VIS-À-VIS PM USING GIS-BASED MODEL
}

M. Memarianfard ${ }^{1, *}$, M. Memarianfard ${ }^{2}$, M. S. Mousavi Aghdam ${ }^{3}$ and H. Memarianfard ${ }^{4}$

${ }^{1}$ Department of Environmental Engineering, K.N.Toosi University of Technology, Tehran, Iran

${ }^{2}$ Department of Civil and Environmental Engineering, Iran

${ }^{3}$ Khak Energy Pars Consultant .Co

${ }^{4}$ Moscow State University of Civil Engineering (National Research University), Moscow, Russia

Published online: 15 May 2016

\begin{abstract}
In megacities, exposure to high concentrations of air pollution, as a major concern on public health, is being felt worldwide problem. The issue of particulate matter especially the $\mathrm{PM}_{2.5}$ has become extremely crucial in Tehran, due to industrialization and population growth. Therefore, it is crucial to estimate the $\mathrm{PM}_{2.5}$ concentrations for the purpose of health risk evaluation. Since the air quality, considering $\mathrm{PM}_{2.5}$ varies over space and time, in this paper, RBF method in a based GIS model was utilized to zone air quality and its health risks upon $\mathrm{PM}_{2.5}$ concentrations dispersion over Tehran, during one year, from 21 March 2013 to 20 March 2014. The RBF method was applied to obtain the zoning maps and determine the highest concentration of $\mathrm{PM}_{2.5}$ in the 22 Tehran's regions for each season. The $\mathrm{RMSE}_{\min }$ values according to the types of functions in the RBF method, viz.: Completely regularized spline, Spline with tension, Multiquadric function, Inverse multiquadric function, and Thin-plate spline, for each month have been assessed. The numbers of neighbors in the model for each function were varied from 3 to 15.
\end{abstract}

Author Correspondence, e-mail: memarian@kntu.ac.ir doi: http://dx.doi.org/10.4314/jfas.v8i3s.176

Journal of Fundamental and Applied Sciences is licensed under a Creative Commons Attribution-NonCommercial 4.0 International License. Libraries Resource Directory. We are listed under Research Associations category. 
The results indicate that the models with 4 neighbors have the best performance with the lowest RMSE values by using RBF method. In accordance with health risks assessment, the most and less favorable health conditions happen during spring and winter respectively. However, the most critical zone is city center.

Keywords: Air pollution; $\mathrm{PM}_{2.5}$; Tehran; Health risks; GIS method; RBF model; Zonation; RMSE.

\section{INTRODUCTION}

In the past few years, the issue of particular matter (PM) had increasing negative impacts on human health and environment, owing to global urbanization and industrialization (Cogliani, 2001; Lee et al., 2011; Yadav et al., 2015; Liu and Cui, 2014). High concentrations of airborne particle in urban areas may precipitate respiratory problems, such as asthma and bronchitis, and also escalate likelihood of human lung cancer and cardiorespiratory mortalities (Pope III et al., 2002; Solomon et al., 2003; Houssaini et al., 2007; Kan et al., 2007; Neuberger et al., 2007; Babin et al., 2008). In contrast with the past, the air quality index with considering PM has exceeded the standard values at more regions in Tehran as an industrialized area.In Tehran, the coarse particles are mixture of various materials which may include metals, ions, minerals, organic content, PAH, soot, microorganism, etc. Further, the researches in the air pollution fields have indicated that an effective solution to spatial dispersion modeling of PM is the application and implementation of a geographic information system (GIS) in which measured data after analyzing can be used for obtaining the zoning maps (Cyrys et al., 2005; Gumusay et al., 2008; Salah et al., 2014; Tang et al., 2010; Vienneau et al., 2012).

In this research, to assess health risks zonation upon $\mathrm{PM}_{2.5}$ and its spatial analysis over Tehran, monthly recorded $\mathrm{PM}_{2.5}$ concentration datasets, during one year, from 21 March 2013 to 20 March 2014 have been collected. To normalize huge number of data, avoiding less effective values, the lag effects are filtered and the concentration data have been implemented on rush hour values upon weighted coefficient. To develop spatial dispersion maps of $\mathrm{PM}_{2.5}$ over Tehran using $\mathrm{RBF}$ method, the authors used the monthly average concentration of $\mathrm{PM}_{2.5}$. In addition, to develop air quality evaluation modeling and health risks zonation in Tehran, the authors used AQI calculator to determine levels of air quality with a significant color over Tehran vis-à-vis $\mathrm{PM}_{2.5}$ concentrations. 


\section{CASE STUDY}

In this study, the data set was collected from the urban air monitoring stations in Tehran. In figure 1, are shown the geographical map and air pollution monitoring stations over Tehran. The stations in Tehran's regions are constantly monitoring air and report the daily data, which are used in this research such as $\mathrm{PM}_{2.5}$ concentrations.

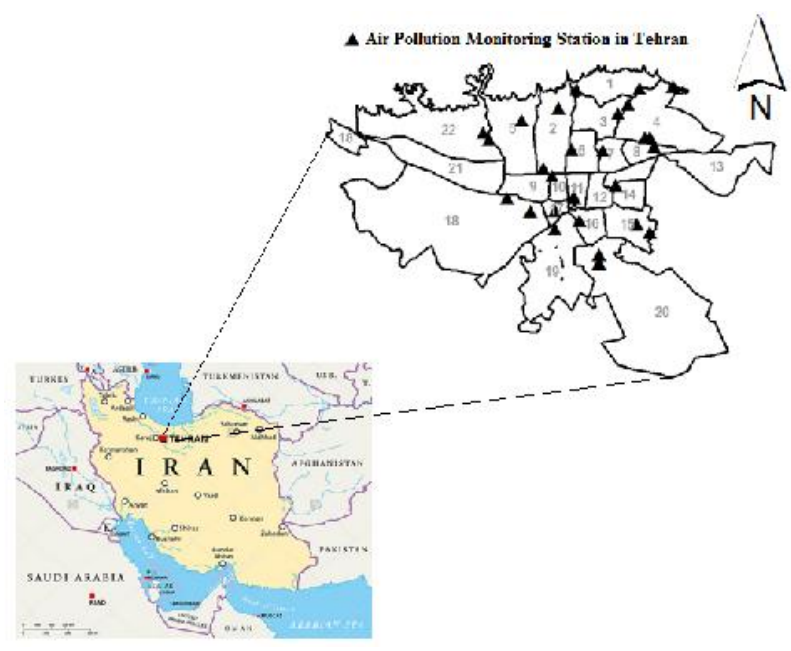

Fig.1. Geographical map and air pollution monitoring stations of Tehran

\section{METHODS}

Since the air pollution dispersion upon $\mathrm{PM}_{2.5}$ concentrations varies over space and time, in this paper, RBF method in a based GIS model was utilized to zone $\mathrm{PM}_{2.5}$ over Tehran, during one year, from 21 March 2013 to 20 March 2014. The RBF method was applied to obtain the zoning maps and determine the highest concentration of $\mathrm{PM}_{2.5}$ in the 22 Tehran's regions for each season. For obtaining health risks zonation maps, the AQI calculator was utilized, so it helps determine levels of health concerns over Tehran with a significant color.

\section{RESULTS}

In this research, the $\mathrm{RMSE}_{\min }$ values according to the number of neighbors and types of functions in the RBF method, such as CRS, SWT, MF, IMF, and TPS for each month have been assessed. Results of predicted RBF model predicted of $\mathrm{PM}_{2.5}$ concentrations over Tehran in the spring and 
winter and the $\mathrm{RMSE}_{\min }$ assessment with considering number of neighbors and types of functions, viz.: CRS, SWT, MF, IMF, and TPS are shown in Figure 2, 3 and table 1. Further, this study presents the health risks map based on AQI calculating in Spring and winter, for various Tehran's regions, in figure 4.

Table 1. Results of the total number of $\mathrm{RMSE}_{\min }$ with considering number of neighbors and type of functions, viz.: CRS, SWT, MF, IMF and TPS.

\begin{tabular}{c|c|c|c|ccc|c}
\hline $\begin{array}{c}\text { Number of } \\
\text { neighbors }\end{array}$ & CRS & SWT & MF & IMF & TPS & Total \\
\hline $\mathbf{3}$ & 3 & 4 & 3 & 2 & 2 & 14 \\
\hline $\mathbf{4}$ & 5 & 4 & 6 & 3 & 5 & 23 \\
\hline $\mathbf{5}$ & 2 & 1 & 2 & 2 & 1 & 8 \\
\hline $\mathbf{6}$ & 1 & 0 & 1 & 1 & 2 & 5 \\
\hline $\mathbf{7}$ & 0 & 1 & 0 & 2 & 0 & 3 \\
\hline $\mathbf{8}$ & 1 & 1 & 0 & 0 & 0 & 2 \\
\hline $\mathbf{9}$ & 0 & 0 & 0 & 1 & 0 & 1 \\
\hline $\mathbf{1 0}$ & 0 & 1 & 0 & 0 & 0 & 1 \\
\hline $\mathbf{1 1}$ & 0 & 0 & 0 & 1 & 1 & 2 \\
\hline $\mathbf{1 2}$ & 0 & 0 & 0 & 0 & 0 & 0 \\
\hline $\mathbf{1 3}$ & 0 & 0 & 0 & 0 & 0 & 0 \\
\hline $\mathbf{1 4}$ & 0 & 0 & 0 & 0 & 1 & 1 \\
\hline $\mathbf{1 5}$ & 0 & 0 & 0 & 0 & 0 & 0 \\
\hline
\end{tabular}




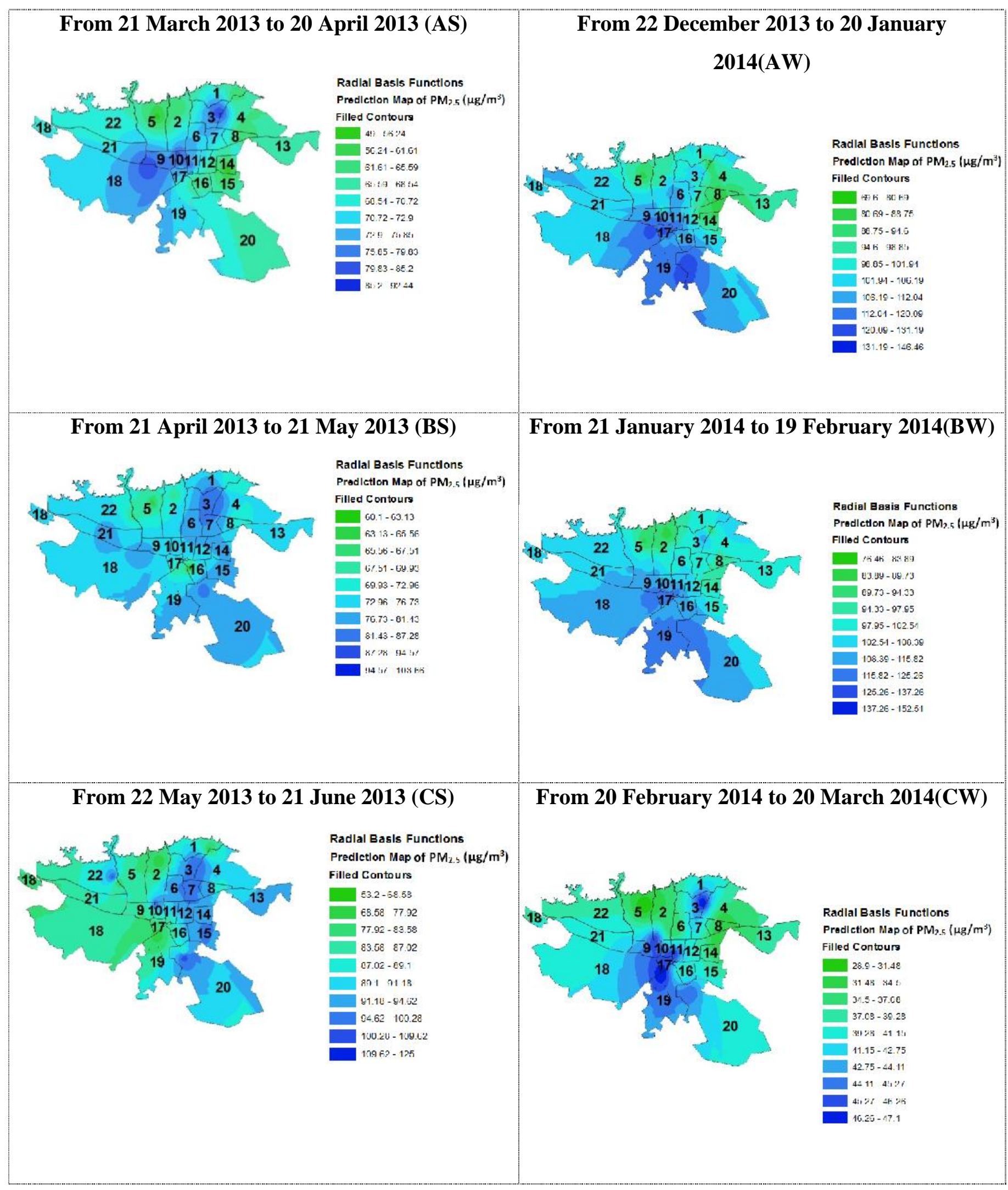


Fig.2. Results of predicted RBF model vis-à-vis $\mathrm{PM}_{2.5}$ concentrations over Tehran in the spring and winter. (AS) from 21 March 2013 to 20 April 2013, (BS) From 21 April 2013 to 21 May 2013, (CS) From 22 May 2013 to 21 June 2013, (AW) From 22 December 2013 to 20 January 2014, (BW) From 21 January 2014 to 19 February 2014, (CW) From 20 February 2014 to 20 

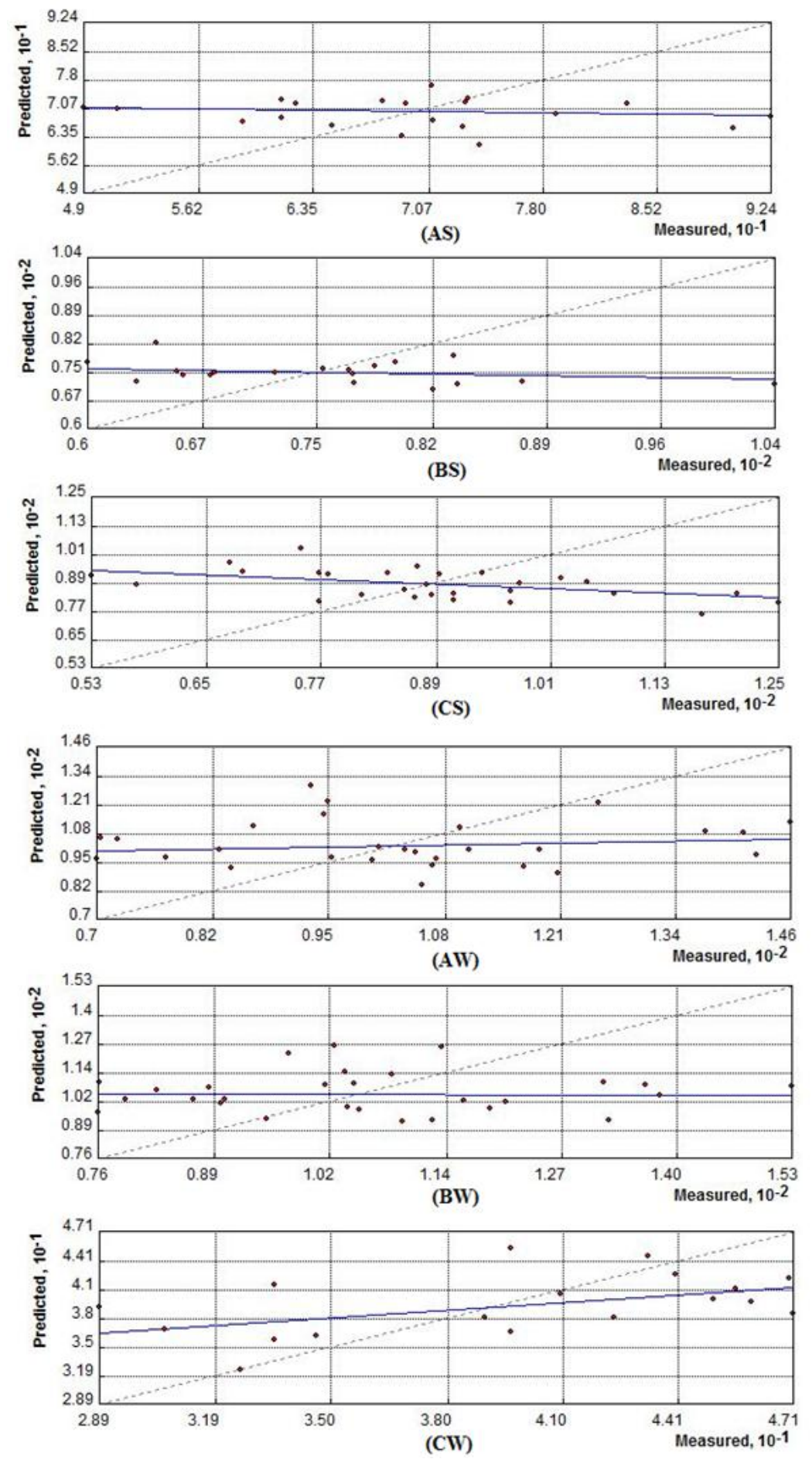

Fig.3. Plots of the measured and predicted concentrations of $\mathrm{PM}_{2.5}$ by using RBF, (AS) from 21 March 2013 to 20 April 2013, (BS) From 21 April 2013 to 21 May 2013, (CS) From 22 May 
2013 to 21 June 2013, (AW) From 22 December 2013 to 20 January 2014, (BW) From 21

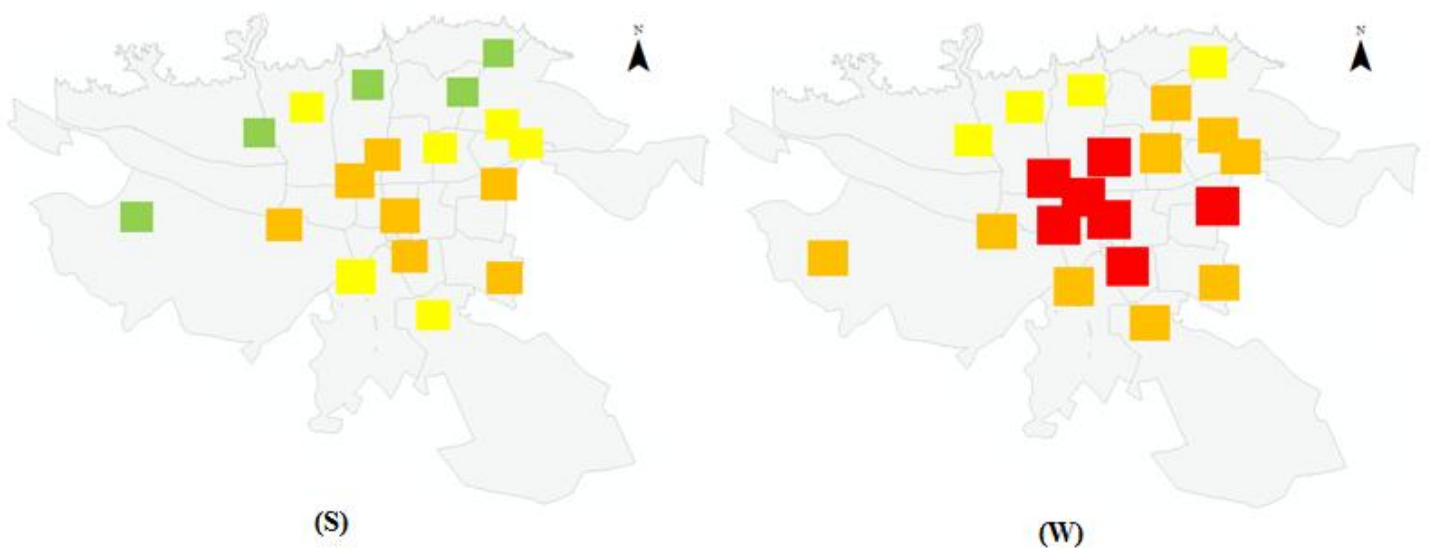

\begin{tabular}{|c|c|c|}
\hline Air Quality index & Levels of health concern & Colors \\
\hline $0-50$ & Good & Green \\
\hline $\mathbf{5 1 - 1 0 0}$ & Moderate & Yellow \\
\hline $101-150$ & Unhealthy for sensitive groups & Orange \\
\hline $151-200$ & Unhealthy & Red \\
\hline $\mathbf{2 0 1 - 3 0 0}$ & Very unhealthy & Purple \\
\hline $\mathbf{3 0 1 - 5 0 0}$ & Hazardous & Marron \\
\hline
\end{tabular}

January 2014 to 19 February 2014, (CW) From 20 February 2014 to 20 March 2014.

Fig.4. Map of health risks zonation based on AQI in Spring and winter and the six levels of health concerns. (S) Spring: from 21 March 2013 to 21 June 2013, (W) Winter: from 22

December 2013 to 20 March 2014

\section{CONCLUSIONS}

In conclusion, RBF spatial prediction method in abased GIS model can be utilized for developing the zoning maps. Hence, it can be used as a tool for distribution air pollution over a megacity. In this paper, the results show that the highest $\mathrm{PM}_{2.5}$ concentrations have been occurred in the winter especially at the center, south, and in some cases at northeast of the Tehran, during the period from 21 march 2013 to 20 march 2014. By performing analysis on the errors, the numbers of neighbors were estimated. In this method, the numbers of neighbors in the model for each function were varied from 3 to 15 . The results indicate that the models with 4 neighbors have the best performance with the lowest RMSE values. Health risks assessment and its zonation with application of AQI calculator indicate that, the most and less favorable health conditions happen 
during spring and winter respectively. However, the most critical zone is city center that is symbolized with red color.

\section{REFERENCES}

[1] Babin, S., H. Burkom, R. Holtry, N. Tabernero, J. Davies-Cole, L. Stokes, K. DeHaan, and D. Lee, 2008, Medicaid patient asthma related acute care visits and their associations with ozone and particulates in Washington, D.C., from 1994-2005: International Journal of Environmental Health Research, v. 18, no. 3, p. 209-222, doi:10.1080/09603120701694091.

[2] Cogliani, E., 2001. Air pollution forecast in cities by an air pollution index highly correlated with meteorological variables. Atmos. Environ. 35, 2871e2877.

[3] Cyrys, J., Hochadel, M., Gehring, U., Hoek, G., Diegmann, V., Brunekreef, B., and Heinrich, J., 2005. GIS-Based estimation of exposure to particulate matter and $\mathrm{NO}_{2}$ in an urban area: Stochastic versus dispersion modeling. Environmental Health perspectives; Vol 3: Number 8.987-992.

[4] Houssaini, A. S., M. Squalli, N. I. Hafida, M. P. Roth, C. Nejjari, and M. N. Benchekroun, 2007, Air pollution as a determinant of asthma among schoolchildren in Mohammedia, Morocco: International Journal of Environmental Health Research, v. 17, no. 4, p. 243-257, doi:10.1080/09603120701372086.

[5] Kan, H. D., S. J. London, G. H. Chen, Y. H. Zhang, G. X. Song, N. Q. Zhao, L. L. Jiang, and B. H. Chen, 2007, differentiating the effects of fine and coarse particles on daily mortality in Shanghai, China: Environment International, v. 33, p. 376 384, doi:10.1016/j.envint.2006.12.001.

[6] Lee, S., Ho, C.H., Choi, Y.S., 2011. High-PM 10 concentration episodes in Seoul, Korea: background sources and related meteorological conditions. Atmos. Environ. 45,7240-7247.

[7] Liu, J., and Cui, S., 2014. Meteorological Influences on Seasonal Variation of Fine Particulate Matter in Cities over Southern Ontario, Canada. Hindawi Publishing Corporation Advances in Meteorology, Volume, Article ID 169476, 15 pages, DOI: $10.1155 / 2014 / 169476$.

[8] M.Umit Gumusay, Alper Unal, Rukiye Aydın, 2008. USE OF GEOGRAPHICAL INFORMATION SYSTEMS IN ANALYZING VEHICLE EMISSIONS: ISTANBUL AS A 
CASE STUDY The International Archives of the Photogrammetry, Remote Sensing and Spatial Information Sciences. Vol. xxxvii. Part B1. Beijing: 997-1000.

[9] Neuberger, M., D. Rabczenkob, and H. Moshammera, 2007, Extended effects of air pollution on cardiopulmonary mortality in Vienna: Atmospheric Environment, v. 41, p. 8549-8556.

[10] Salah A. H. S., Bahaa, Z., Hasan G., 2014. Mapping Dispersion of Urban Air Particulate Matter Over Kirkuk City Using Geographic Information System. Journal of Environment and Earth Science Vol.4, No.8 : 80 - 87.

[11] Solomon, C., J. Poole, L. Jarup, K. Palmer, and D. Coggon, 2003, Cardio respiratory morbidity and long-term exposure to particulate air pollution: International Journal of Environmental Health Research, v. 13, no. 4, p. 327-335, doi:10.1080/09603120310001616100.

[12]Tao Tang, Wenji Zhao, Huili Gong, Xiaojuan Li, Ke Zang,Joel D. Bernosky, Wenhui Zhao, and Shanshan Li ,2010.GIS spatial analysis of population exposure to fine particulate air pollution in Beijing, China Environmental Geosciences, v. 17, no. 1 :pp. 1-16.

[13]Vienneau, D., de Hoogh, K., and Briggs, D., 2012. A GIS-based method for modelling air pollution exposures across Europe. Science of the Total Environment 408, 255-266.

[14] Yadav, S., Praveen, O., \& Gursumeeran Satsangi. P., 2015. The effect of climate and meteorological changes on particulate matter in Pune, India. Environ Monit Assess 187: 402.

\section{How to cite this article:}

Memarianfard M, Memarianfard M, Mousavi Aghdam M. S and Memarianfard H. Health risks zonation in megacities vis-à-vis pm using gis-based model. J. Fundam. Appl. Sci., 2016, 8(3S), 193-202. 